\section{Sintomas de universitários dependentes da internet e busca do equilíbrio psicoemocional e autocontrole da agressividade}

Batista, Marcos Antonio

Universidade do Vale do Sapucaí - UNIVÁS. e-mail: marcosantoniobatista@gmail.com

\section{Dias, Gilmara Aparecida dos Reis}

Universidade do Vale do Sapucaí - UNIVÁS.

\section{Balducci, Camila Clementino}

Universidade do Vale do Sapucaí - UNIVÁS.

PALAVRAS-CHAVE: Inteligência; Percepção; Bioética; Vulnerabilidade.

Há um consenso entre diversos autores que mudanças na sociedade afetam o indivíduo. A internet se interpenetrou em nosso meio e vem modificando não só o social, mas a forma como os sujeitos subjetivam seus desejos e necessidades. Foram encontrados fatores relevantes no uso intensivo da internet, chegando-se inclusive à hipótese da dependência. Mudanças como essas podem afetar o modo como lidamos, enquanto profissionais, com estes sujeitos remetendo-nos ao risco de perdemos nossa capacidade de avaliação e auxílio. Considerando o compromisso Bioético que temos com a sociedade e com o campo cientifico, qual seja, o de estar a par de transformações que acarretam mudanças no antigo modo de ver a personalidade e a subjetividade humana, pensou-se em estudar o fenômeno internet e sua capacidade de intervir na vulnerabilidade de algumas pessoas. Esta pesquisa teve como objetivo descrever as características psicológicas mais proeminentes aos usuários da internet, verificar a existência de fatores causadores da dependência neste veículo de comunicação, bem como analisar diferenças entre os grupos contrastantes enquanto sexo, idade e curso de graduação com relação a variável dependência de relacionamentos virtuais. A pesquisa foi realizada com estudantes de ambos os sexos com idade acima de 18 anos matriculados nos primeiros anos dos cursos de Biologia, Ciências Contábeis, Enfermagem, Engenharia de Produção, Fisioterapia e Psicologia de uma universidade no interior de Minas Gerais. Teve delineamento quantitativo, descritivo, transversal, analítico e correlacional. Para coleta de dados foram utilizados um Questionário Sóciodemográfico elaborado pelos pesquisadores e dois testes de personalidade, o Inventário de Habilidades Sociais e Escala Fatorial de Neuroticismo, ambos aprovados e recomendados pelo Conselho Federal de Psicologia. As respostas dadas pelos alunos serão compiladas no software SPSS versão 20, específico para pesquisa na área social e as variáveis foram submetidas à análises estatísticas, descritivas, análise fatorial e posteriormente as foram correlacionadas entre si na busca de evidência de validade convergente. Por meio da Análise Fatorial chegou-se a um instrumento com 3 fatores que representaram a dependência de uso da internet. O Fator 1 reuniu itens relacionados à apreensão e expectativas para se manter conectado à internet; o Fator 2 referiu as frustações e perdas relacionais virtuais e o Fator 3 concentrou itens ligados às dificuldades para se desligar do mundo online. Os participantes mais jovens apresentaram mais expectativas e apreensões para se manter conectados no mundo virtual e frustações por perdas em relacionamentos. Não houve diferenças por sexo pela técnica do Teste $t$ de Student e, a ANOVA mostrou que os participantes do curso de Engenharia de Produção mostraram mais frustrados com perdas em relacionamentos afetivos virtuais. Estes achados contribuem de certa forma para análise e elaboração de estratégias de atendimento a esta possível modalidade psicopatológica contemporânea.

AGRADECIMENTOS. Agradecemos à Universidade do Vale do Sapucaí - Pró-Reitoria de Pós-Graduação e Pesquisa da Univás pelo apoio a esta pesquisa por meio do incentivo aos projetos do Programa de Iniciação Científica - Pibic.

\section{REFERÊNCIAS}

[1] Young, K. Internet addiction: the emergence of a new disorder. (1986) Disponível em 06/03/2014, acessado em http://www.netaddiction.com

[2] Silveira, M. D. P. Efeitos da globalização e da sociedade em rede via Internet na formação de identidades contemporâneas. Psicologia: Ciência e Profissão. 24 (4), pp. 42-51. (2004)

[3] Nicolaci-da-Costa, A. M. Internet: a negatividade do discurso da mídia versus a positividade da experiência pessoal. À qual dar crédito? Estudos de Psicologia (Natal). 7 (1), pp. 25-36. (2002b).

[4] Nicolaci-da-Costa, A. M. Primeiros contornos de uma nova configuração psíquica. Cad. CEDES. 25 (65), pp. 7185. (2005).

[5] Greenfield, D. As propriedades de dependência do uso de internet. De Young, K. S., Abreu, C. N. at al, em Dependência de Internet - Manual e Guia de Avaliação e Tratamento (pp. 169 a 190). Artmed. (2011). 